\title{
VASCULAR ABNORMALITIES ASSOCIATED WITH PSEUDOXANTHOMA ELASTICUM
}

BY

\author{
H. H. WOLFF, J. F. STOKES and B. E. SCHLESINGER \\ From University College Hospital, London
}

(RECEIVD FOR PURUCATION APRIL 12, 1951)

Evidence has been presented by several authors that the skin condition known as pseudoxanthoma elasticum may be associated with widespread abnormalities of the blood vessels of the limbs and viscera (Sandbacka-Holmström, 1939; Touraine, 1940, 1941; Carlborg, 1944; Guenther, 1946; Scheie and Freeman, 1946; Revell and Carey, 1948).

The term pseudoxanthoma elasticum was first used by Darier (1896) to describe a dermatological condition characterized histologically by degeneration and fragmentation of the elastic tissue in the dermis. Clinically, the skin becomes flaccid and can be lifted off the underlying tissue to an abnormal degree. When it is stretched, yellow or fieshcoloured papules and irregular streaks become visible in the affected region. The yellow discoloration has given rise to the term pseudoxanthoma but apart from this superficial resemblance the condition is not related to xanthomatosis. The lesions are more or less symmetrically distributed and are commonly found in the neck, axillae and groins but may occur elsewhere, particularly on the abdomen and in the antecubital and popliteal fossae. The condition usually starts before the age of $\mathbf{3 0}$ and may be familial (Cockayne, 1933).

The first indication that the changes in the skin are part of a more generalized abnormality was the discovery by Grönblad $(1929,1932)$ and Strandberg (1929) that pseudoxanthoma elasticum is frequently associated with angioid streaks in the fundi. This association has since been known as the GrönbladStrandberg syndrome. Angioid streaks are brown, reddish or grey streaks which are found near the disc or radiate from it towards the periphery. Retinal haemorrhages, particularly at the maculae, and evidence of retino-choroidal degeneration may also be present and may at times be found even in the absence of angioid streaks (Batten, 1931 ; Benedict and Montgomery, 1935).

The nature of angioid streaks has been discussed by several authors including Batten (1931), Benedict and Montgomery (1935), Franceschetti and Roulet (1936), Law (1938), Scholz (1941), Ebert (1943), Winkelman (1948) and Verhoeff (1948). Duke-Elder (1940) considers that angioid streaks are probably the result of ruptures in the elastic membrane of Bruch of the choroid. This view is supported by the histological findings of Böck (1938) and Hagedoorn (1939), and more recently by Verhoeff (1948), all of whom found degenerative changes in the elastic tissue of Bruch's membrane and breakso in its continuity.

In addition to the degeneration of elastic tissue in the skin and choroid, similar changes have also been demonstrated in the aorta and brachial arteries (Urbach and Wolfram, 1938) and in the vessels of the jejunum and ileum and, to a lesser extent, in the coronary arteries (Prick, 1938). These findings were based on post-mortem studies of two patients with pseudoxanthoma elasticum and angioid streaks who died at the ages of 44 and 48 . The changes in the elastic tissue of the blood vessels were similar to those seen in the skin and choroid and were not thought to be due to arteriosclerosis. Touraine $(1940,1941)$ puts forward the view that the skin changes of pseudoxanthoma elasticum are only one aspect of a widespread familial disorder of elastic tissue affecting the skin, the eyes and the blood vessels. He refers to this disorder as ' l'élastorrhexie systématisée'. Böck (1938) and Parkes Weber (1948) use the term 'elastosis dystrophica' to describe the same condition.

There is a considerable amount of clinical evidence to support the view that the peripheral blood vessels are involved in the pathological process underlying pseudoxanthoma elasticum. In a monograph on the circulatory abnormalities in the arteries to the limbs Carlborg (1944) has reviewed the literature, and he was able to demonstrate diminished pulsation and a reduced pulse wave 
velocity in 14 out of 15 patients with pseudoxanthoma elasticum. Four of his 15 patients had definite symptoms of intermittent claudication which had begun at the age of 18 in one case, at 36 in another and during the fifth decade in the remaining two. Intermittent claudication since childhood has been reported in a man with pseudoxanthoma elasticum and angioid streaks (Scheie and Freeman, 1946). When this patient was examined at the age of 26 no pulsation could be felt in either the dorsalis pedis or posterior tibial artery. Calcification was visible radiologically in the arteries of the thighs. Several of Carlborg's cases also had calcification in the arteries of the limbs. In two of these the calcification was demonstrated at the ages of 27 and 32. All the others were over 40.

The clinical evidence of involvement of the visceral blood vessels is less complete. Carlborg (1944) draws attention to the fact that several of his patients had symptoms suggestive of angina pectoris. As most of these patients were over 40 , arteriosclerotic changes could have been responsible for these symptoms as well as for the calcification in the peripheral arteries mentioned previously.

Gastro-intestinal haemorrhages have been reported in association with pseudoxanthoma elasticum by several authors. Thus in one patient haematemeses occurred at the ages of 17 and 18 (Carlborg, 1944, case 2), and in another five times between the ages of 24 and 35 (Chauffard, 1889). Terminal bleeding into the gastro-intestinal tract was seen by Tannenhain (1901) in an arteriosclerotic woman aged 74, and by Hagedoorn (1939) in a woman aged 48. Revell and Carey (1948) report a patient with pseudoxanthoma elasticum and angioid streaks who had a haematemesis at the age of 14 , two further ones at the age of 29 and melaena at the age of 30 . The same authors report another patient in whom a profuse gastro-intestinal haemorrhage occurred at the age of 28 and in whom pseudoxanthoma elasticum was associated with angioid streaks, hypertension and absent peripheral pulses. They suggest that the haemorrhages in these two cases were due to 'systemic pseudoxanthoma elasticum'.

A boy in whom pseudoxanthoma was associated with fundal changes, absent peripheral pulses, intermittent claudication and recurrent gastrointestinal haemorrhages has been under observation by one of us (B.E.S.) since 1945 when he was 9 years old. This appears to be the first case in which all these abnormalities have been found in the same patient and at such an early age.

\section{Case Report}

G.R. was a 9-year-old boy when he was first seen at The Hospital for Sick Children, Great Ormond Street, in August, 1945. He complained of pain in the calves



Frg. 1.-Lax, inelastic skin on the abdominal wall due to pseudoxanthoma elasticum in a boy aged 9 .

which came on whenever he was running or walking fast. Apart from the fact that the skin on the abdomen was unusually lax, no abnormality was noticed on examination. A radiograph of the hip joints was normal but revealed calcification in both femoral arteries.

In June, 1947, he was admitted to the hospital on account of a sudden onset of melaena. He was pale and weak. The skin was abnormally lax on the abdomen (Fig. 1) and to a lesser extent also in the neck, axillae, antecubital fossae and in the upper parts of the thighs. Yellowish flecks were seen in the skin in the same areas. There were numerous small dots around the discs, at the maculae and in the periphery of the fundi (Fig. 2). Some of these dots were ill-defined and yellow, others were white and glistening. There was some pigmentary degeneration and small areas of choroido-retinal degeneration were present. No angioid streaks were seen. Both radial pulses were absent. The liver was palpable. Otherwise clinical examination revealed no abnormality.

Haemoglobin was $60 \%$ with $2,800,000$ red cells per c.mm. The white cell and platelet count, bleeding and clotting time, and the bone marrow were all normal. A chest radiograph showed fine, uniform punctate opacities which were distributed evenly throughout the left lung fields (Fig. 3). The right lung was normal. A radiograph of the skull was normal. The blood cholesterol was $209 \mathrm{mg}$. per $100 \mathrm{ml}$. Biopsy of the skin (Fig. 4) showed the typical changes of pseudoxanthoma elasticum. The elastic fibres were fragmented and condensed into irregular whorls. An electron microphotograph taken later demonstrated that despite this abnormal arrangement of fibres the component fibrils were normal in appearance (Fig. 5).

He was treated with a blood transfusion and iron, and discharged after three weeks with a haemoglobin of $95 \%$. He had a further small haematemesis followed by melaena in February, 1948, and a larger one in April, 1948, when he had to be readmitted. Haemoglobin had 


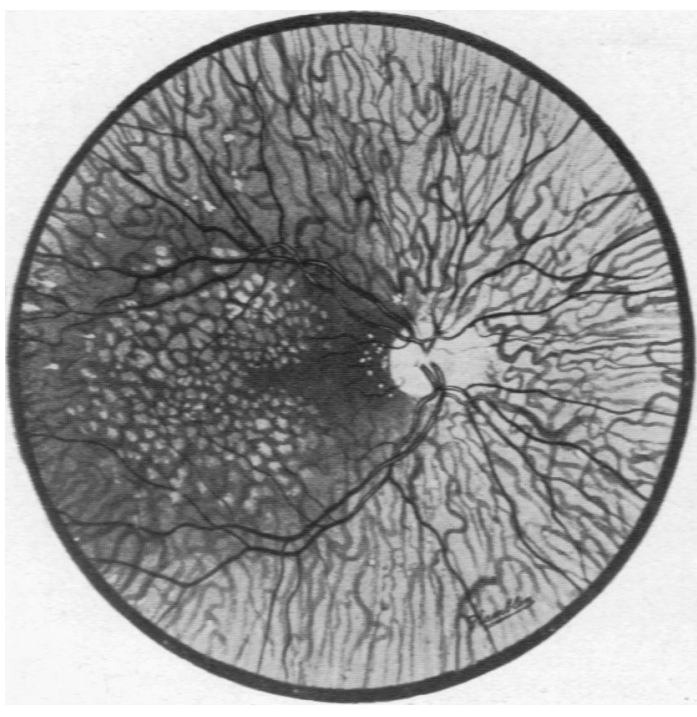

Fig. 2.-Drawing of the fundus of the same patient showing pale dots thought to be colloid bodies and areas of pigmentary degeneration.

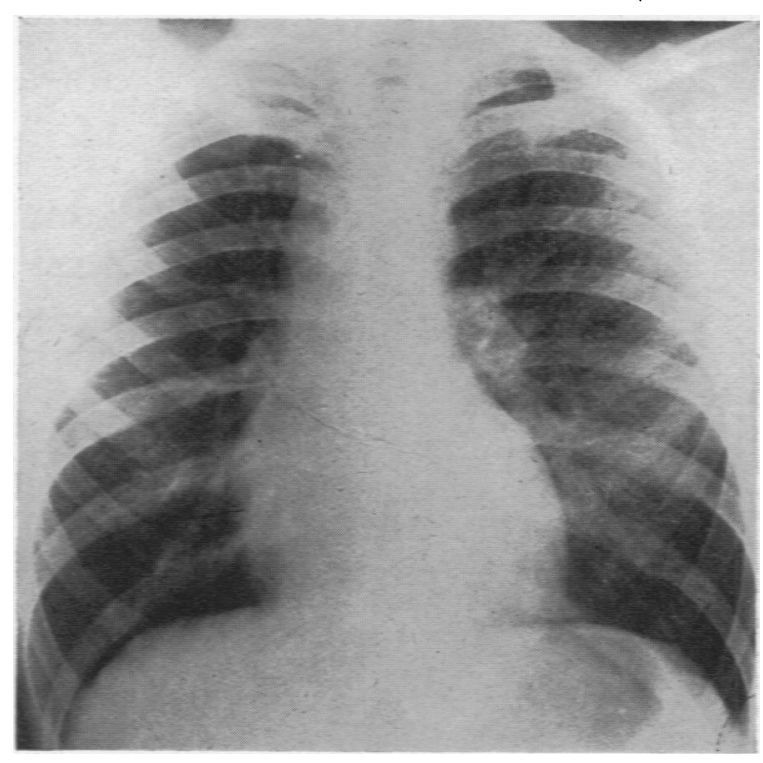

Fig. 3.-Chest radiograph showing miliary mottling in the left lung fields of the same patient.
Frg. 4.-Biopsy of the skin showing fragmentation of the elastic tissue (Lawson's elastic stain $\times 45$ ).






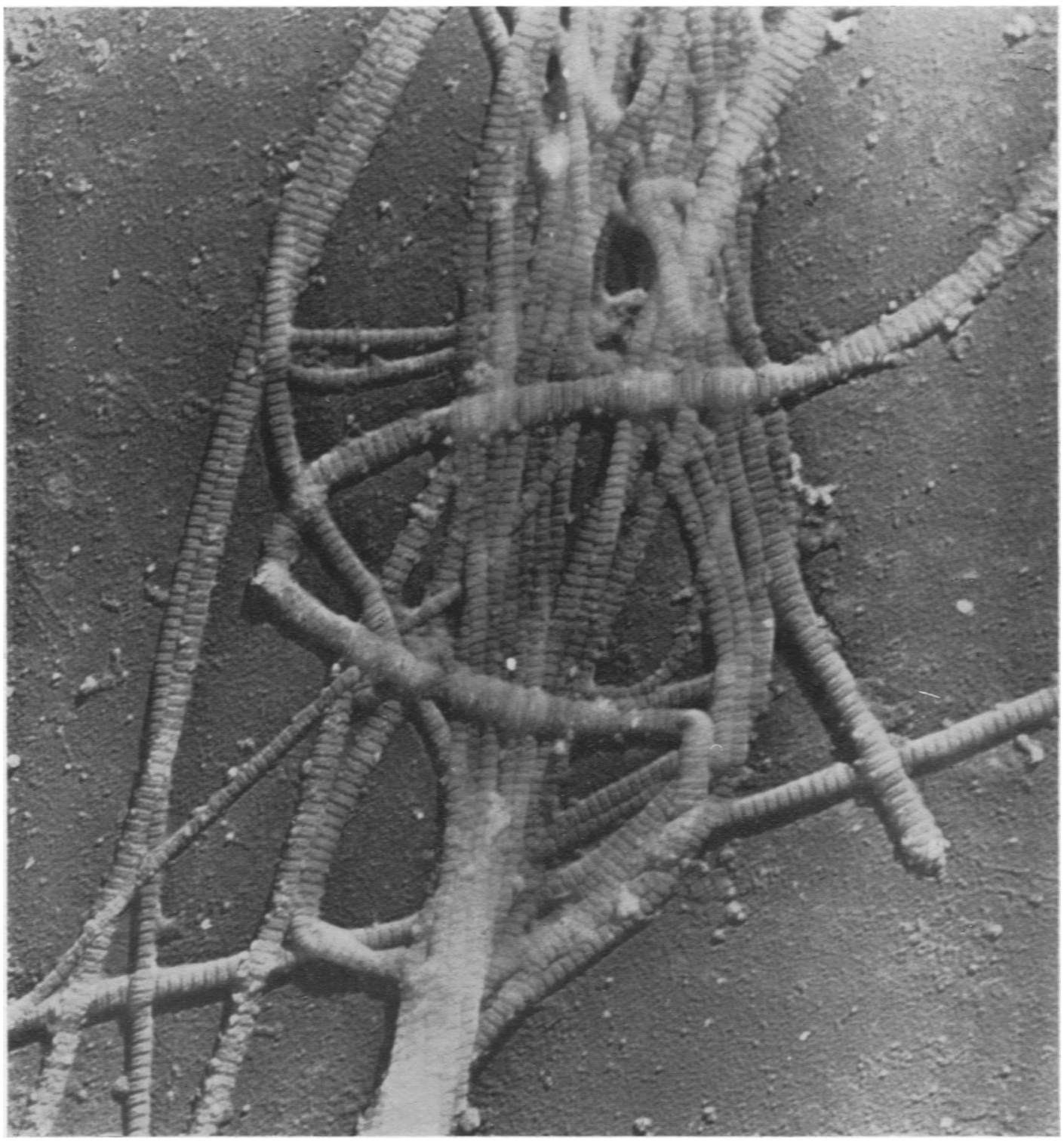

FIG. 5.-Teased out subcutaneous tissue showing that the component fibrils of the elastic fibres are normal in structure. (Electron photomicrograph $\times 45,000$.) 
fallen to $68 \%$ and he was again treated by transfusion. A barium meal and barium swallow in July, 1948, revealed no abnormality. A further small haematemesis occurred in March, 1949.

In April, 1950, he was admitted to University College Hospital. Three days before admission he had suddenly felt faint and sick. The next day he vomited blood and his motions became loose and black. He was still complaining of pain in the calves on rapid walking. The pain was always relieved by standing still. It never came on at rest or when he was walking slowly.

On admission he was pale but not shocked. The skin condition was essentially unchanged. The fundi revealed the same changes which had been noted previously, but again no angioid streaks. The multiple yellow and white dots were thought to be due to colloid bodies arising from the elastic membrane of Bruch.

The peripheral blood vessels revealed several abnormalities. No pulsation could be detected in either radial or ulnar artery or in the dorsalis pedis and posterior tibial arteries. Faint pulsation could be felt in an aberrant vessel in the midline of the fiexor surface of both forearms just above the wrists. A loud systolic bruit was audible over both femoral arteries. This was loudest on the right side where a thrill could also be felt. Oscillometry revealed no pulsation in either leg below the knee. In spite of the absence of the peripheral pulses the hands and feet were warm and normal in colour. The blood pressure could not be recorded over the right brachial artery but was $120 / 70 \mathrm{~mm}$. $\mathrm{Hg}$ in the left arm. Examination of the heart, lungs, abdomen and nervous system was normal. There were a few enlarged cervical lymph nodes, mainly on the left.

Haemoglobin was $74 \%$ with $3,670,000$ red cells per c.mm. The white cell and platelet count, the bleeding and clotting time, and the capillary fragility test were again normal. A chest radiograph still showed the same uniform, miliary mottling in the left lung fields. A barium meal three weeks after the haematemesis was normal. A radiograph of the legs showed cakification in both femoral and popliteal arteries and a 2 in. shortening of the left tibia. Faint calcification was present in the axillary arteries. The serum calcium level was $10.5 \mathrm{mg} . \%$, the inorganic phosphorus $3.1 \mathrm{mg} . \%$ and the alkaline phosphatase 13 units. Urinary examination and an electrocardiogram were normal.

He was treated by transfusion and discharged after three weeks. He remained well until September, 1950, when he had another attack of melaena for which he was treated at Hammersmith Hospital under Dr. J. G. Scadding. Gastroscopy by Dr. F. Avery Jones two weeks after the onset of melaena showed no abnormality in the oesophagus or stomach. Plethysmographic studies showed that the resting blood flow in the legs and arms was in the upper range of normal.

Family History. One brother, H.R., aged 25 when seen in University College Hospital in 1950, also gave a history of pain in the calves on rapid walking since childhood. The pain was relieved by standing still and never occurred when be walked at an ordinary pace. He gave no history of haematemesis or melaena. On examination he was found to have the skin changes of pseudoxanthoma elasticum on the abdominal wall, in the neck, axillae and groins. These changes had previously been noted when he was 11 years old. Biopsy at that time at The Hospital for Sick Children, Great Ormond Street, had confirmed the diagnosis of pseudoxanthoma elasticum. The fundi showed several white and yellow dots of the same type as those seen in G.R. and were thought to be due to colloid bodies. Angioid streaks were not seen. Neither the dorsalis pedis nor posterior tibial artery was palpable. Pulsation in the radial arteries could only be felt with dificulty. A systolic bruit was audible over both brachial arteries. The systolic blood pressure was $130 \mathrm{~mm}$. Hg. The diastolic pressure could not be ascertained on account of the loud systolic bruit. Radiographs showed extensive calcification in both femoral arteries. A chest radiograph was normal.

Two sisters were said to be normal. Two other children had died in infancy, one of pneumonia and one of gastroenteritis, and there had been one miscarriage The mother was alive and well. The father had died of carcinoma of the bronchus. The parents were not consanguineous.

\section{Discussion}

This case supports the view that the skin condition of pseudoxanthoma elasticum is only one aspect of a more widespread disease of elastic tissue in which the eyes and the peripheral and gastro-intestinal blood vessels, and possibly those of other organs may also be involved. Although Carlborg (1944) has previously demonstrated diminished pulsation and calcification in the arteries of the limbs in patients with pseudoxanthoma elasticum, many of his subjects were over $\mathbf{4 0}$ and arteriosclerotic changes may have been responsible for some of his findings. In the case described, and in his brother, intermittent claudication had been present since early childhood. Calcification in the femoral arteries was clearly visible radiologically at the age of 9 , and at the age of 14 no pulsation could be detected in the distal arteries of the arms or legs.

Cariborg (1944) considers that the reduction or loss of arterial pulsation in the limbs is not due to occlusion of the lumen but is a consequence of the degeneration and fragmentation of elastic tissue in the vessel wall. If the elastic tissue in the wall of a medium-sized artery degenerates, the arterial wall will mainly consist of smooth muscle and some connective tissue. Such a vessel is, in his opinion, unable to transmit pulsation normally even if the lumen is patent. The fact that in the present case the resting blood flow was normal, in spite of the absence of arterial pulsation, can be interpreted as supporting Carlborg's hypothesis. The alternative explanation is that there is some obliteration of the lumen and that the normal resting flow is the result of a well-developed anastomotic circulation. Biopsy of a non-pulsatile ulnar artery in a case of the 
Grönblad-Strandberg syndrome (Scheie and Freeman, 1946) suggests that both factors may play a part. The lumen of the vessel was found to be smaller than normal but it was not occluded. There was thickening of the vessel wall due to hyperplasia of the muscular coat and the elastic tissue showed degeneration and fragmentation. In addition there was evidence of a well-developed anastomotic circulation.

The extensive calcification in the peripheral arteries presumably occurs as a secondary phenomenon in the areas in which the elastic tissue has degenerated. Calcification has also been observed in the affected areas of the skin (Finnerud and Nomland, 1937).

It appears reasonable to explain the recurrent gastro-intestinal haemorrhages in this and other cases by assuming that similar changes have occurred in the blood vessels of the gastro-intestinal tract as suggested previously by Carlborg (1944) and by Revell and Carey (1948). This assumption is supported by the fact that in the case described by Prick (1938) and Hagedoorn (1939), in which a terminal gastro-intestinal haemorrhage had occurred, tortuous, thickened vessels were found to be projecting into the lumen of the intestines at necropsy. Degeneration of elastic tissue and calcification could be demonstrated in the wall of these vessels.

It is much more difficult to account for the uniform miliary opacities which were demonstrated in the left lung fields of this patient. The appearances at first suggested the possibility of a previous lipiodol examination but no such investigation had ever been made. Miliary tuberculosis, sarcoidosis and lipoidosis can all be excluded on clinical grounds. The only record of changes in the lungs in association with pseudoxanthoma elasticum is found in a case reported by Balzer (1884). His patient had several haemoptyses and was found at necropsy to have cavities at the apices which were regarded as being due to fibro-caseous tuberculosis. On microscopy the elastic tissue in the alveolar walls of both lungs showed extensive degeneration and fragmentation similar to the changes found in the affected areas of the skin.

It is suggested that in our case the elastic tissue of the inter-alveolar septa and of the small pulmonary blood vessels has undergone similar degenerative changes. Such destruction of elastic tissue might lead to multiple small haemorrhages into the alveoli and the $x$-ray appearance might be due to the resultant haemosiderin deposits as in pulmonary haemosiderosis from other causes (Anspach, 1939; Scott, Park and Lendrum, 1947). In this connexion it is of interest that in idiopathic pulmonary haemosiderosis extensive damage of elastic tissue has frequently been found in the inter-alveolar septa and small pulmonary blood vessels and this has been regarded as the primary abnormality in this condition by several authors (Ceelen, 1931; Glanzmann and Walthard, 1941; Wyllie, Sheldon, Bodian and Barlow, 1948). Others, however, consider that the histological changes found in the elastic tissue are secondary to the deposition of the iron-containing pigment (Lendrum, Scott and Park, 1950). No case with symptoms of idiopathic pulmonary haemosiderosis has so far been described in which pseudoxanthoma elasticum, angioid streaks or abnormalities of the peripheral arteries have been observed.

The absence of haemoptyses in our patient does not necessarily rule out the possibility that the radiological changes in the lung are due to deposits of haemosiderin. Haemosiderosis of cardiac origin (Lendrum, Scott and Park, 1950) and idiopathic pulmonary haemosiderosis (Pilcher and Eitzen, 1944) have both been found in patients who had never had a haemoptysis. The main difficulty in accepting this, or any other explanation, of the miliary opacities observed is the fact that they are confined to one lung only. Their cause remains obscure.

\section{Summary}

The literature on the association of pseudoxanthoma elasticum with vascular abnormalities in the limbs and viscera is reviewed.

The case of a boy of 14 is described in whom pseudoxanthoma elasticum is associated with intermittent claudication since early childhood, absence of pulsation in the distal arteries of the limbs, calcification in the proximal arteries, recurrent haemorrhages into the gastro-intestinal tract, abnormalities in the fundi, miliary mottling in the left lung fields and unexplained shortening of one tibia. The patient's brother has also had intermittent claudication since childhood and in addition to pseudoxanthoma elasticum and changes in the fundi he has diminished pulsation in the distal arteries of the limbs and calcification in the femoral arteries at the age of 25 .

This case supports the view that the skin condition of pseudoxanthoma elasticum is only one aspect of a more generalized, familial disease of elastic tissue in which Bruch's membrane of the choroid and the blood vessels of the limbs and viscera, including the lungs, may also be involved.

Our thanks are due to Dr. J. G. Scadding for permission to use his medical records, Dr. F. Avery Jones for the gastroscopy, Dr. M. Bodian for the original skin 
biopsy. Dr. R. N. Tattersall for the electron microphotograph, and the staffs of the photographic departments of University College Hospital and The Hospital for Sick Children, Great Ormond Street.

\section{REFERENCES}

Anspach. W. E. (1939). Amer. J. Roentgenol., 41, 592. Balzer, F. (1884). Arch. Physiol. norm. path., 3 ser., 4, 65.

Batten, R. D. (1931). Brit. J. Ophthal., 15, 279.

Benedict., W. L. and Montgomery, H. (1935). Amer. J. Ophthal., 18, 205.

Böck, J. (1938). Z. Augenheilk., 95, 1.

Carlborg. U. (1944). Acta med. scand., suppl. 151, 1.

Ceelen. W. (1931). Handbuch der speziellen pathologischen Anatomie und Histologie,' ed. F. Henke and $O$. Lubarsch, vol. 3, part 3, p. 20. Berlin.

Chauffard, A. (1889). Bull. Soc. méd. Hôp. Paris 3, ser. 6,412 .

Cockayne, E. A. (1933). - Inherited Abnormalities of the Skin, p. 319 . London.

Darier, J. (1896). Mh. prakt. Derm., 23, 609.

Duke-Elder, W. S. (1940). Textbook of Ophthalmology,' vol. 3, p. 2413 . London.

Ebert, R. H. (1943). Arch. Derm. Syph., Chicago, 48, 75.

Finnerud, C. W. and Nomland, R. (1937). Ibid., 35, 653.

Franceschetti, A. and Roulet, E. L. (1936). Arch. Ophthal., Paris, 53, 401.

Glanzmann, E. and Walthard, B. (1941). Mschr. Kinderheilk., 88, 1.

Grönblad, E. (1929). Acta ophthal., Kbh., 7, 329.

- (1932). Ibid., 10, suppl. 1, 1.
Guenther, E. (1946). Acta med. scand., 123, 482.

Hagedoorn, A. (1939). Arch. Ophthal., Chicago, 21, $746,935$.

Law, F. W. (1938). Trans. ophthal. Soc. U.K., 58, I, 191.

Lendrum, A. C., Scott, L. D. W. and Park, S. D. S. (1950). Quart. J. Med., 19, 249.

Pilcher, J. D. and Eitzen, O. (1944). Amer. J. Dis. Child.. 67, 387.

Prick, J. J. G. (1938). Doctoral treatise, Maastrichr. Quoted by Carlborg (1944).

Revell, S. T. R. and Carey, T. N. (1948). Sth. med. J. Bgham, Ala., 41, 782.

Sandbacka-Holmström, I. (1939). Acta. derm.-venereol.. Stockh., 20, 684.

Scheie, H. G. and Freeman, N. E. (1946). Arch. Ophthal., Chicago, 35, 241.

Scholz, R. O. (1941). Ibid., 26, 677.

Scott, L. D. W., Park, S. D. S. and Lendrum, A. C. (1947). Brit. J. Radiol., 20, 100.

Strandberg. J. (1929). Z. Haut- u. GeschlKr., 31, 689.

Tannenhain, E. G. v. (1901). Wien. klin. Wschr.. 14, 1038.

Touraine. A. (1940). Bull. Soc. franç. Derm. Siph., 44, 255. (1941). Pr. méd., 49, 361.

Urbach, E. and Wolfram, S. (1938). Arch. Derm. Syph., Wien, 176, 167.

Verhoeff, F. H. (1948). Brit. J. Ophthal., 32, 531.

Weber, F. Parkes (1948). - Modern Trends in Dermatology,' p. 315. London.

Winkelman, J. E. (1948). Ophthalmologica, Basel, 115, 84.

Wyllie, W. G., Sheldon, W., Bodian, M. and Barlow, A. (1948). Quart. J. Med., 17, 25. 